\title{
Oral Hygiene Controllability and Personality Type Test (MBTI)
}

Hye Sook Park

\author{
Department of Dental Laboratory Technology, Shingu College, Seongnam, Korea
}

Received January 15, 2014 Revised January 29, 2014 Accepted February 10, 2014
Correspondence to:

Hye Sook Park

Department of Dental Laboratory

Technology, Shingu College, 377,

Gwangmyeong-ro, Jungwon-gu,

Seongnam 462-743, Korea

Tel: $+82-31-740-1575$

Fax: +82-31-740-1589

E-mail: hspark@shingu.ac.kr
Purpose: The purpose of this study was to investigate the relationship between personality type and oral hygiene controllability.

Methods: Four hundred eighty-two college students in Gyeonggi-do completed the MyersBriggs type indicator (MBTI) and a questionnaire and collected data were analyzed by SAS 9.2 program.

Results: Compared to extroverted subjects, a significantly increased percentage of introverted subjects demonstrated oral malodor and stress $(p<0.05)$. Tongue coating and stress seemed to occur the most frequently in intuition-feeling (NF) type, while oral malodor seemed to occur the most frequently in sensation-feeling (SF) type among four fuctional types. Tongue coating and stress seemed to occur the most frequently in NF type, while oral malodor seemed to occur the most frequently in sensation-perceiving (SP) type among four temperaments. Significantly increased mean scales of tongue scraping index and oral hygiene controllability index were found for extroverts $(\mathrm{p}<0.05)$. Mean scales of tooth brushing index and oral hygiene controllability index appeared to be the highest in NF type among four fuctional types. Mean scales of tongue scraping index and oral hygiene controllability index appeared to be the highest in sensation-judging (SJ) type among four temperaments.

Conclusions: Oral hygiene controllability was associated with personality type and it is necessary to develop oral health education program considering personality type.

Key Words: MBTI; Oral hygiene; Personality; Questionnaires

\section{INTRODUCTION}

In modern society, oral health has been considered as an important factor to maintain a well-being life. Therefore, attention to oral hygiene care has been more increasing than the past. The key point for oral hygiene care is said to be to remove the dental plaque. ${ }^{1)}$

Oral malodor of oral etiology may result from excessive microbial metabolism on the tongue dorsum, and periodontium, periodontal disease, excessive caries, poor oral hygiene, oral ulcers, food impaction, unclean denture and dry mouth. ${ }^{2-4)}$

People under stressful conditions may show dry mouth ${ }^{5}$ and decreased salivary production can lead to increased risk of unfavorable oral condition. ${ }^{6}$ Stress is one type of the interaction between the individual and environment. ${ }^{7)}$ All individuals differ in the way that they relate to, or interpret their environments and the way is said to reflect their individual personality.

The Myers-Briggs type indicator (MBTI) delineates personality types based on Jungian typology and identifies preferences for four dichotomous dimensions: 'extroversion' versus 'introversion', ‘sensation' versus 'intuition', ‘thinking' versus 'feeling,, and 'judging' versus 'perceiving,'

There is a previous study on the relation of personality preference and performance level..$^{10)}$ Bakdash and Proshek ${ }^{11)}$ showed that oral hygiene status was related to personal and academic profiles. Reports on attitude and behavior of oral health care have been also suggested. ${ }^{12,13)}$ However to date, no analysis of oral hygiene performance and personality type has been performed. The aim of this study was to assess the association between oral hygiene controllability

Copyright (c) 2014 Korean Academy of Orofacial Pain and Oral Medicine. All rights reserved. 
and personality type and to use the result for oral health education.

\section{MATERIALS AND METHODS}

\section{Subjects}

Data were collected from 482 college students in Gyeonggido, including 233 men and 249 women. Mean age of the subjects was $21.1 \pm 3.0$ years (Table 1 ).

\section{Data Collection}

Data were obtained in September and October of 2013. After explaining MBTI, the examiner distributed the MBTI GS form to students and retrieved completed replies at their classroom. Moreover, the students were asked to answer the

Table 1. Demographics of the subjects

\begin{tabular}{lll}
\hline Sex & Subject & Age $(\mathrm{y})$ \\
\hline Men & $233(48.3)$ & $21.4 \pm 2.9$ \\
Women & $249(51.7)$ & $20.9 \pm 3.1$ \\
Total & $482(100.0)$ & $21.1 \pm 3.0$ \\
\hline
\end{tabular}

Values are presented as number (\%) or mean \pm standard deviation. prepared questionnaire (Fig. 1) containing items on selfevaluation of tongue coating, oral malodor, stress, and habit related to tooth brushing and tongue scraping and also returned the completed answers.

Collected MBTI replies were analysed and scored according to routine MBTI analysis. ${ }^{14)}$ To assess quantitavely and objectively the oral hygiene habit, frequency of tooth brushing per day was rated on the following 1 to 4 rating scale, where 1 indicated once, 2 indicated twice, 3 indicated three times, and 4 indicated four times or more per day. ${ }^{15)}$ Time needed for each brushing was rated on the following 1 to 5 rating scale, where 1 indicated less than 30 seconds, 2 indicated from 30 seconds to 1 minute, 3 indicated more than 1 minute to 2 minutes, and 4 indicated more than 2 minutes to 3 minutes, 5 indicated more than 3 minutes. ${ }^{15)}$ Thus, tooth brushing index was defined as follows: tooth brushing index=frequency of tooth brushing per day (score 1, 2, 3, 4)xtime needed for each brushing (score 1, 2, 3, 4, 5). ${ }^{15)}$ In addition, tongue scraping index which scored the frequency of tongue scraping was estimated on a scale of 2 , 4, 8 as follows: $2=$ not fixed; $4=$ once per day; $8=$ with tooth brushing. ${ }^{16)}$ Furthermore, tongue scraping index added to

\section{Questionnaire}

$\begin{array}{lrrr}\text { Name of College : } & \text { Name of Department : } & \text { Grade : } \\ \text { Name : } & \text { Birthday : } & \text { Age : } & \text { Gender : }\end{array}$

Please answer the following questions by checking the one answer which describes you.

1. Have you experienced tongue coating?
1) Frequently experienced
2) Sometimes experienced
3) Not experienced

2. Do you feel your oral malodor?
1) No
2) Slightly feel
3) Strongly feel

3. Are you under stressful condition due to academic or other difficulties?

$\begin{array}{ll}\text { 1) Yes } & \text { 2) No }\end{array}$

4. How many times do you brush your teeth per day?
1) Once
2) Twice
3) Three times
4) Four times or more

5. How long do you brush your teeth per each brushing?
1) Less than 30 seconds
2) 30 Seconds- 1 minute
3) 1-2 Minutes
4) 2-3 Minutes
5) More than 3 minutes

6 . Do you scrape your tongue?
1) Yes
2) No

7. When do you scrape your tongue if you checked "Yes" in question \#6?
1) Together with tooth brushing
2) Once per day
3) Not fixed

Thank you for your cooperation.

Fig. 1. Form and contents of questionnaire. 
tooth brushing index made oral hygiene controllability index, that is, oral hygiene controllability index=tooth brushing index+tongue scraping index. ${ }^{15,16)}$

\section{Statistical Analyses}

All the statistical analyses were performed by SAS 9.2 program (SAS Institute Inc., Cary, NC, USA). The chi-square test was used to evaluate the relationship of personality types to self-reporting prevalence rate of tongue coating, oral malodor, and stress. Student's t-test and one-way ANOVA were performed to evaluate the difference of mean scales of tooth brushing index, tongue scraping index and oral hygiene controllability index according to personality types.

\section{RESULTS}

Two hundred twenty-five (46.9\%) subjects have experienced tongue coating among whom 32 (6.7\%) frequently experienced and 193 (40.2\%) sometimes experienced (Table 2). Three hundred sixty-one (75.7\%) subjects felt oral malodor among whom 347 (72.8\%) slightly felt and 14 (2.9\%) strongly felt (Table 2). Two hundred sixty-nine (55.8\%) subjects were under stressful condition (Table 2). With respect to four preferences of personality, extroversion (E) type was demonstrated by 266 (55.2\%), introversion (I) type by 216 (44.8\%), sensation $(\mathrm{S})$ type by 379 (78.6\%), intuition $(\mathrm{N})$ type by 103 (21.4\%), thinking (T) type by 302 (62.7\%), feeling (F) type by 180 (37.3\%), judging (J) type by 270 (56.0\%) and perceiving (P) type by 212 (44.0\%) (Table 2). Compared to extroverted subjects, a significantly increased percentage of introverted subjects demonstrated oral malodor and stress $(\mathrm{p}<0.05)$ (Table 2$)$. Tongue coating and oral malodor seemed to occur more frequently in $\mathrm{F}$ type than in $\mathrm{T}$ type (Table 2). S type and $\mathrm{P}$ type appeared to have higher prevalence of oral malodor than $\mathrm{N}$ type and $\mathrm{J}$ type, respectively (Table 2).

Regarding four psychological functions (sensation-thinking

Table 2. Prevalence of tongue coating, oral malodor and stress according to 4 pairs of preference tendency

\begin{tabular}{|c|c|c|c|c|c|c|c|c|}
\hline \multirow{2}{*}{$\begin{array}{l}\text { Item number and } \\
\text { symptom }\end{array}$} & \multicolumn{8}{|c|}{ Four pairs of preferences } \\
\hline & $\begin{array}{c}E \\
266(55.2)\end{array}$ & $\begin{array}{c}\text { I } \\
216(44.8)\end{array}$ & $\begin{array}{c}S \\
379(78.6)\end{array}$ & $\begin{array}{c}\mathrm{N} \\
103(21.4)\end{array}$ & $\begin{array}{c}\mathrm{T} \\
302(62.7)\end{array}$ & $\begin{array}{c}\mathrm{F} \\
180(37.3)\end{array}$ & $\begin{array}{c}J \\
270(56.0)\end{array}$ & $\begin{array}{c}P \\
212(44.0)\end{array}$ \\
\hline $\begin{array}{l}\text { 1. Tongue coating } \\
225(46.9)\end{array}$ & $\begin{array}{c}121 \\
(45.5)\end{array}$ & $\begin{array}{c}104 \\
(48.2)\end{array}$ & $\begin{array}{c}175 \\
(46.2)\end{array}$ & $\begin{array}{c}50 \\
(48.5)\end{array}$ & $\begin{array}{c}136 \\
(45.0)\end{array}$ & $\begin{array}{c}89 \\
(49.4)\end{array}$ & $\begin{array}{c}134 \\
(49.6)\end{array}$ & $\begin{array}{c}91 \\
(42.9)\end{array}$ \\
\hline $\mathrm{p}$-value & \multicolumn{2}{|c|}{0.5606} & \multicolumn{2}{|c|}{0.6691} & \multicolumn{2}{|c|}{0.3477} & \multicolumn{2}{|c|}{0.1430} \\
\hline $\begin{array}{l}\text { 2. Oral malodor } \\
361 \text { (75.7) }\end{array}$ & $\begin{array}{c}188 \\
(70.7)\end{array}$ & $\begin{array}{c}173 \\
(80.1)\end{array}$ & $\begin{array}{c}288 \\
(76.0)\end{array}$ & $\begin{array}{c}73 \\
(70.9)\end{array}$ & $\begin{array}{c}223 \\
(73.8)\end{array}$ & $\begin{array}{c}138 \\
(76.7)\end{array}$ & $\begin{array}{c}195 \\
(72.2)\end{array}$ & $\begin{array}{c}166 \\
(78.3)\end{array}$ \\
\hline $\mathrm{p}$-value & \multicolumn{2}{|c|}{$0.0177^{*}$} & \multicolumn{2}{|c|}{0.2884} & \multicolumn{2}{|c|}{0.4889} & \multicolumn{2}{|c|}{0.1265} \\
\hline $\begin{array}{l}\text { 3. Stress } \\
269(55.8)\end{array}$ & $\begin{array}{c}137 \\
(51.5)\end{array}$ & $\begin{array}{c}132 \\
(61.1)\end{array}$ & $\begin{array}{c}213 \\
(56.2)\end{array}$ & $\begin{array}{c}56 \\
(54.4)\end{array}$ & $\begin{array}{c}175 \\
(58.0)\end{array}$ & $\begin{array}{c}94 \\
(52.2)\end{array}$ & $\begin{array}{c}152 \\
(56.3)\end{array}$ & $\begin{array}{c}117 \\
(55.2)\end{array}$ \\
\hline p-value & \multicolumn{2}{|c|}{$0.0347 *$} & \multicolumn{2}{|c|}{0.7400} & \multicolumn{2}{|c|}{0.2209} & \multicolumn{2}{|c|}{0.8080} \\
\hline
\end{tabular}

E, extroversion type; I, introversion type; $\mathrm{S}$, sensation type; $\mathrm{N}$, intuition type; $T$, thinking type; $\mathrm{F}$, feeling type; J, judging type; $\mathrm{P}$, perceiving type. Values are presented as number (\%).

${ }^{*}$ p-values were completed by chi-square test.

Table 3. Prevalence of tongue coating, oral malodor and stress according to four psychological functions

\begin{tabular}{|c|c|c|c|c|c|}
\hline \multirow[b]{2}{*}{ Item number and symptom } & \multicolumn{5}{|c|}{ Four functions } \\
\hline & $\begin{array}{c}\text { NF } \\
51(10.6)\end{array}$ & $\begin{array}{c}\text { NT } \\
52(10.8)\end{array}$ & $\begin{array}{c}\text { SF } \\
129(26.7)\end{array}$ & $\begin{array}{c}\text { ST } \\
250(51.9)\end{array}$ & p-value \\
\hline 1. Tongue coating & $27(52.9)$ & $23(44.2)$ & $62(48.1)$ & $113(45.2)$ & 0.7416 \\
\hline 2. Oral malodor & $39(76.5)$ & $34(65.4)$ & $99(76.7)$ & 189 (75.6) & 0.4122 \\
\hline 3. Stress & $31(60.8)$ & $25(48.1)$ & 63 (48.8) & $150(60.0)$ & 0.1071 \\
\hline
\end{tabular}

NF, intuition-feeling; NT, intuition-thinking; SF, sensation-feeling; ST, sensation-thinking.

Values are presented as number (\%).

p-values were completed by chi-square test. 
[ST], sensation-feeling [SF], intuition-thinking [NT], intuition-feeling [NF]), ST type was shown by 250 (51.9\%), SF type by 129 (26.7\%), NT type by 52 (10.8\%) and NF type by 51 (10.6\%) (Table 3). Tongue coating and stress seemed to occur the most frequently in NF type, while oral malodor seemed to occur the most frequently in SF type (Table 3).

Concerning four temperaments (sensation-perceiving [SP], sensation-judging [SJ], NT, NF), SP type was exhibited by 142 (29.4\%), SJ type by 237 (49.2\%), NT type by $52(10.8 \%)$ and NF type by 51 (10.6\%) (Table 4). Tongue coating and stress seemed to occur the most frequently in NF type, while oral malodor seemed to occur the most frequently in SP type (Table 4).

Significantly increased mean scales of tongue scraping index and oral hygiene controllability index were found for extroverts $(\mathrm{p}<0.05)$ (Table 5). Mean scales of tooth brushing index, tongue scraping index and oral hygiene controllability index appeared to be higher in J type than in P type (Table 5).

Mean scales of tooth brushing index and oral hygiene controllability index appeared to be the highest in NF type (Table 6).

Mean scales of tongue scraping index and oral hygiene

Table 4. Prevalence of tongue coating, oral malodor and stress according to four temperaments

\begin{tabular}{|c|c|c|c|c|c|}
\hline \multirow[b]{2}{*}{ Item number and symptom } & \multicolumn{5}{|c|}{ Four temperaments } \\
\hline & $\begin{array}{c}\text { NF } \\
51(10.6)\end{array}$ & $\begin{array}{c}\text { NT } \\
52(10.8)\end{array}$ & $\begin{array}{c}\text { SJ } \\
237(49.2)\end{array}$ & $\begin{array}{c}\text { SP } \\
142(29.4)\end{array}$ & p-value \\
\hline 1. Tongue coating & $27(52.9)$ & $23(44.2)$ & $120(50.6)$ & $55(38.7)$ & 0.1106 \\
\hline 2. Oral malodor & $39(76.5)$ & $34(65.4)$ & $177(74.7)$ & $111(78.2)$ & 0.3361 \\
\hline 3. Stress & $31(60.8)$ & $25(48.1)$ & $131(55.3)$ & $82(57.8)$ & 0.5691 \\
\hline
\end{tabular}

NF, intuition-feeling; NT, intuition-thinking; SJ, sensation-judging; SP, sensation-perceiving.

Values are presented as number (\%).

p-values were completed by chi-square test.

Table 5. Mean scales of tooth brushing index, tongue scraping index and oral hygiene controllability index according to 4 pairs of preference tendency

\begin{tabular}{|c|c|c|c|c|c|c|c|c|}
\hline \multirow{2}{*}{ Index } & \multicolumn{8}{|c|}{ Four pairs of preferences } \\
\hline & $\mathrm{E}$ & I & $S$ & $\mathrm{~N}$ & $\mathrm{~T}$ & $\mathrm{~F}$ & $\mathrm{~J}$ & $\mathrm{P}$ \\
\hline Tooth brushing index $(8.4 \pm 3.5)$ & $8.6 \pm 3.6$ & $8.2 \pm 3.5$ & $8.4 \pm 3.6$ & $8.6 \pm 3.4$ & $8.4 \pm 3.4$ & $8.5 \pm 3.7$ & $8.6 \pm 3.6$ & $8.2 \pm 3.5$ \\
\hline $\mathrm{p}$-value & \multicolumn{2}{|c|}{0.5606} & \multicolumn{2}{|c|}{0.7133} & \multicolumn{2}{|c|}{0.7731} & \multicolumn{2}{|c|}{0.1441} \\
\hline Tongue scraping index $(6.8 \pm 2.6)$ & $7.1 \pm 2.4$ & $6.5 \pm 2.8$ & $6.8 \pm 2.6$ & $6.8 \pm 2.7$ & $6.8 \pm 2.6$ & $6.8 \pm 2.6$ & $6.9 \pm 2.5$ & $6.6 \pm 2.7$ \\
\hline $\mathrm{p}$-value & \multicolumn{2}{|c|}{$0.0248^{*}$} & \multicolumn{2}{|c|}{0.8867} & \multicolumn{2}{|c|}{0.9321} & \multicolumn{2}{|c|}{0.1859} \\
\hline Oral hygiene controllability index $(15.2 \pm 4.8)$ & $15.7 \pm 4.6$ & $14.7 \pm 5.0$ & $15.2 \pm 4.8$ & $15.3 \pm 4.6$ & $15.2 \pm 4.7$ & $15.3 \pm 4.9$ & $15.6 \pm 4.7$ & $14.8 \pm 4.9$ \\
\hline $\mathrm{p}$-value & \multicolumn{2}{|c|}{$0.0304^{*}$} & \multicolumn{2}{|c|}{0.8461} & \multicolumn{2}{|c|}{0.7952} & \multicolumn{2}{|c|}{0.0716} \\
\hline
\end{tabular}

E, extroversion type; I, introversion type; S, sensation type; N, intuition type; T, thinking type; F, feeling type; J, judging type; P, perceiving type. Values are mean \pm standard deviation.

${ }^{*}$ p-values were completed by Student's t-test.

Table 6. Mean scales of tooth brushing index, tongue scraping index and oral hygiene controllability index according to four psychological functions

\begin{tabular}{lrrrrr}
\hline & \multicolumn{4}{c}{ Four functions } \\
\cline { 2 - 6 } \multicolumn{1}{c}{ Index } & \multicolumn{1}{c}{ NF } & NT & SF & ST & p-value \\
\hline Tooth brushing index & $8.7 \pm 3.6$ & $8.4 \pm 3.1$ & $8.4 \pm 3.7$ & $8.4 \pm 3.5$ & 0.9457 \\
Tongue scraping index & $6.7 \pm 2.7$ & $6.8 \pm 2.7$ & $6.9 \pm 2.6$ & $6.8 \pm 2.6$ & 0.9952 \\
Oral hygiene controllability index & $15.5 \pm 4.9$ & $15.2 \pm 4.4$ & $15.3 \pm 4.9$ & $15.2 \pm 4.8$ & 0.9872 \\
\hline
\end{tabular}

$N F$, intuition-feeling; NT, intuition-thinking; SF, sensation-feeling; ST, sensation-thinking.

Values are mean \pm standard deviation.

p-values were completed by one-way ANOVA. 
Table 7. Mean scales of tooth brushing index, tongue scraping index and oral hygiene controllability index according to four temperaments

\begin{tabular}{|c|c|c|c|c|c|}
\hline \multirow{2}{*}{ Index } & \multicolumn{5}{|c|}{ Four temperaments } \\
\hline & NF & NT & SJ & SP & $\mathrm{p}$-value \\
\hline Tooth brushing index & $8.7 \pm 3.6$ & $8.4 \pm 3.1$ & $8.6 \pm 3.6$ & $8.1 \pm 3.6$ & 0.6108 \\
\hline Tongue scraping index & $6.7 \pm 2.7$ & $6.8 \pm 2.7$ & $7.0 \pm 2.4$ & $6.5 \pm 2.8$ & 0.4845 \\
\hline Oral hygiene controllability index & $15.5 \pm 4.9$ & $15.2 \pm 4.4$ & $15.6 \pm 4.7$ & $14.7 \pm 5.1$ & 0.3706 \\
\hline
\end{tabular}

$N F$, intuition-feeling; NT, intuition-thinking; SJ, sensation-judging; SP, sensation-perceiving.

Values are mean \pm standard deviation.

$p$-values were completed by one-way ANOVA.

controllability index appeared to be the highest in SJ type (Table 7).

\section{DISCUSSION}

Both dental plaque and tongue are important sources of oral malodor with most of the odor emanating from the dorso-posterior surface of the tongue. ${ }^{17)}$ Oral malodor might be caused mainly by tongue coating in the younger generation. ${ }^{18)}$ Oral hygiene procedures such as tooth brushing and tongue scraping decrease caries, gingivitis and periodontitis that may increase the incidence and intensity of oral malodor. $^{19)} 75.7 \%$ of subjects in this study felt oral malodor, though Park et al. ${ }^{20)}$ reported that prevalence rate of oral malodor of Korean was 58.2\% (Table 2).

The MBTI identifies four preferences. Knowledge of psychological preferences enables individuals to look at themselves in relation to others and to environment. ${ }^{21)} \mathrm{E}$ versus I preference concerns a person's mechanism of interacting with the external environment and people. ${ }^{8)}$ While extroverts have optimistic and relaxed attitude and unload their emotions, introverts have pessimistic and anxious attitude and bottle up their emotions. ${ }^{22,23)}$ It was found that I type had more stress than E type in kindergarten teachers. ${ }^{24)}$ It was reported that the decrease in salivary secretion was associated with emotional change. ${ }^{25)}$ It was suggested that subjects with oral malodor showed the decreased amount of salivary secretion. ${ }^{26)}$ These findings explain the significantly increased percentage of introverted subjects of this study in occurrence of oral malodor and stress $(p<0.05)$ (Table 2).

Combination of perception (S, N) and judgment (T, F) produces four functional types (ST, SF, NT, NF). ${ }^{23)}$ Distribution of four types in this study was ST (51.9\%), SF (26.7\%), NT $(10.8 \%)$, and NF (10.6\%) (Table 3). This finding is similar to the finding for high school students in which distribution of four types was ST (53.9\%), SF (26.4\%), NT (12.4\%), and NF (7.3\%). ${ }^{27)}$ Whereas SF type and NF type handle things with personal warmth, ST type and NT type handle things with impersonal analysis. ${ }^{23)}$ While SF type is sympathetic and NF type is enthusiastic, ST type is practical and NT type is logical. ${ }^{23)}$ Previous study suggested that the level of mental health of NF type seemed to be low in nursing students. ${ }^{28)}$ Mitchell et al. ${ }^{29)}$ indicated that psychophysiologic disorder such as hypertension and heart disease occurred more frequently in SF type than in other types. These characteristics of each type may support the result that tongue coating and stress seemed to occur the most frequently in NF type and oral malodor seemed to occur the most frequently in SF type (Table 3).

Four temperaments of the MBTI (SP, SJ, NT, NF) correspond to Hippocrates' temperaments (sanguine, melancholic, choleric, phlegmatic) and to the Greek gods (Dionysian, Epimetheus, Prometheus, Apollinian), ${ }^{30)}$ respectively. Four temperaments of this study exhibited the distribution of SJ (49.2\%), SP (29.4\%), NT (10.8\%), and NF (10.6\%) which is comparable to the finding of SJ (57.1\%), SP (27.1\%), NT (11.8\%), and NF (4.1\%) in medical pofessionals ${ }^{31)}$ (Table 4). NF type is emotionally sensitive and SP type is impulsive. ${ }^{30)} \mathrm{SP}$ type was more frequent than other types among patients with hypertension or heart disease which is stress-related disease. $^{29)}$ These traits may be consistent with the result that tongue coating and stress seemed to occur the most frequently in NF type and oral malodor seemed to occur the most frequently in SP type (Table 4).

Oral hygiene controllability is closely related to level of knowledge and attitude about oral health. ${ }^{32)}$ The higher level of knowledge and attitude about oral health care is, the higher level of oral hygiene performance is. ${ }^{33)}$

In contrast with introverts, extroverts tend to be actionoriented and have positive attitude. ${ }^{22)}$ Vogel et al. ${ }^{34)}$ studied 
the relationship between the amount of plaque and personality traits: the more introverted the individual, the higher the individual's plaque score. Lim $^{10)}$ indicated that performance approach level was higher in extroverts than in introverts. These findings explain the result that significantly increased mean scales of tongue scraping index and oral hygiene controllability index were found for extroverts $(\mathrm{p}<0.05)$ (Table 5).

As opposed to $\mathrm{P}$ type, $\mathrm{J}$ type is industrious and well-organized. ${ }^{22)}$ Chae ${ }^{35)}$ demonstrated that $\mathrm{J}$ type showed higher academic achievement than $\mathrm{P}$ type. These findings may explain the result that mean scales of tooth brushing index, tongue scraping index and oral hygiene controllability index appeared to be higher in J type than in P type (Table 5).

$\mathrm{Kim}^{36)}$ reported that NT type among four fuctional types showed the highest academic achievement in junior college students. Huh ${ }^{37)}$ suggested that NT type and ST type showed higher academic achievement than SF type and NF type in high school students. These findings are not comparable to my result that mean scales of tooth brushing index and oral hygiene controllability index appeared to be the highest in NF type (Table 6).

SJ type tends to be orderly and dependable. ${ }^{22)}$ Kim et al. ${ }^{38)}$ reported that SJ type among four temperaments had the highest academic achievement in medical students. These findings support the result that mean scales of tongue scraping index and oral hygiene controllability index appeared to be the highest in SJ type (Table 7).

In conclusion, the purpose of this study was to investigate the relationship between personality type and oral hygiene controllability. Four hundred eighty-two college students in Gyeonggi-do completed the MBTI and a questionnaire and collected data were analyzed by SAS 9.2 program. The obtained results were as follows:

1. Compared to extroverted subjects, a significantly increased percentage of introverted subjects demonstrated oral malodor and stress $(\mathrm{p}<0.05)$.

2. Tongue coating and stress seemed to occur the most frequently in NF type, while oral malodor seemed to occur the most frequently in SF type among four fuctional types.

3. Tongue coating and stress seemed to occur the most frequently in NF type, while oral malodor seemed to occur the most frequently in SP type among four temperaments.

4. Significantly increased mean scales of tongue scraping index and oral hygiene controllability index were found for extroverts $(\mathrm{p}<0.05)$.

5. Mean scales of tooth brushing index and oral hygiene controllability index appeared to be the highest in NF type among four fuctional types.

6. Mean scales of tongue scraping index and oral hygiene controllability index appeared to be the highest in SJ type among four temperaments.

Therefore, oral hygiene controllability was associated with personality type and it is necessary to develop oral health education program considering personality type.

\section{CONFLICT OF INTEREST}

No potential conflict of interest relevant to this article was reported.

\section{REFERENCES}

1. Kim YK, Moon HS, Jung JY, et al. A study on the oral health awareness and behavior in the higher grades of elementary school. J Korean Soc School Health 2001;14:73-81.

2. Kostelc JG, Preti G, Zelson PR, Brauner L, Baehni P. Oral odors in early experimental gingivitis. J Periodontal Res 1984;19:303-312.

3. Yaegaki K, Sanada K. Biochemical and clinical factors influencing oral malodor in periodontal patients. J Periodontol 1992;63:783789.

4. Lu DP. Halitosis: an etiologic classification, a treatment approach, and prevention. Oral Surg Oral Med Oral Pathol 1982;54:521-526.

5. Chang BY, Kim SH, Chun YH, Hong JP. An effect of endocrinological changes related to the stress on the submandibular gland in rats. Korean J Oral Med 2000;25:279-291.

6. Kho HS, Lee SW. Influences of saliva substitutes on salivary enzymatic activity. Korean J Oral Med 2009;34:227-235.

7. Auvenshine RC. Psychoneuroimmunology and its relationship to the differential diagnosis of temporomandibular disorders. Dent Clin North Am 1997;41:279-296.

8. Boyd R, Brown T. Pilot study of Myers Briggs type indicator personality profiling in emergency department senior medical staff. Emerg Med Australas 2005;17:200-203.

9. Havens SE. Comparisons of Myers-Briggs and enneagram types of registered nurses [master's thesis]. Gainesville: University of Florida; 1995. pp. 16-22.

10. Lim SR. Relation of personality preference, and achievement goal orientation, academic self-efficacy, test anxiety in selecting dental hygiene students. J Korean Soc Dent Hyg 2010;10:1025-1035.

11. Bakdash MB, Proshek JM. Oral hygiene status of dental students as related to their personal and academic profiles. J Periodontal Res 1979;14:438-443.

12. Lee MJ. Knowledge, belief, attitude and behavior concerning oral hygiene in healthcare and non-healthcare students. J Korean Soc Dent Hyg 2003;3:169-182.

13. Lee ES, Ra SJ, Han MD, Kim HC, Kwon HS. A study on the awareness for oral health among health personnels in hospital. J 
Korean Acad Dent Health 1999;23:139-149.

14. Kendall E. Myers Briggs type indicator. European English ed. Oxford: Oxford Psychologists Press; 1998.

15. Han KS. A study on the factors affecting feeling of oral malodor. Korean J Oral Med 2002;27:255-269.

16. Park JH, Han KS, Kim MG. Effect of tongue scraping, $\mathrm{ZnCl} 2$ mouth rinse, and periodontal treament on the reduction of oral malodor. Korean J Oral Med 2000;25:41-51.

17. Tonzetich J. Production and origin of oral malodor: a review of mechanisms and methods of analysis. J Periodontol 1977;48:1320.

18. Miyazaki H, Sakao S, Katoh Y, Takehara T. Correlation between volatile sulphur compounds and certain oral health measurements in the general population. J Periodontol 1995;66:679-684.

19. Sulser GF, Brening RH, Fosdick LS. Some conditions that effect the odor concentration of breath. J Dent Res 1939;18:355-359.

20. Park MS, Kim YK, Chung SC, Lee SW. Epidemiologic study on oral malodor for Korean. Korean J Oral Med 2001;26:107-114.

21. Hirsh SK. Using the Myers-Briggs type indicator in organizations. 2nd ed. Palo Alto: Consulting Psychologists Press; 1991.

22. Myers IB, McCaulley MH. Manual: a guide to the development and use of the Myers-Briggs type indicator. Palo Alto: Consulting Psychologists Press; 1985.

23. Myers IB, Myers PB. Gifts differing. Palo Alto: Consulting Psychologists Press; 1980.

24. Kim SY, Lee JY. The relationship between kindergarten teachers' personality types and job stress in teaching. J Future Early Child Educ 2004;11:305-330.

25. Rhodus NL. Xerostomia and the geriatric patient. Dentistry 1988;8:12-17.

26. Kim KE. The relation of salivary secretion, the oral care and the oral malodor [master's thesis]. Seoul: Graduate School of Social Development, Chung-Ang University; 2001.

27. Cho WP. An analysis of the difference of high school students' stress coping behavior by personality type [master's thesis].
Chungbuk: Graduate School, Korea National University of Education; 1997.

28. Kim HS. The relationship among personality type, self-esteem and mental health of nursing students. J Korean Acad Psych Mental Health Nurs 2003;12:385-393.

29. Mitchell WD, Culig KM, Circerchi J, Casper M, Byyny RL, LoVerde M. Type similarity of hypertensives and patients with heart disease. J Psychological Type 1991;21:54-58.

30. Kim JT, Shim HS, Lim SH. My appearance, my face. Seoul: Korean Psychology Test Research Center; 1993.

31. Song GH. A study on socio-psychological stress and stress coping style by the personality types of medical professionals [master's thesis]. Seoul: Graduate School of Education, Konkuk University; 2005.

32. Murray JJ. The prevention of oral disease. 3rd ed. New York: Oxford University Press; 1996.

33. Kim HK. A Study of related factors on self oral hygiene behaviors of the adult population in the workplace [master's thesis]. Seoul: Graduate School of Health, Yonsei University; 2001.

34. Vogel R, Morante EA, Ives C, Diamond R. Relationship of personality traits and periodontal disease. Psychosomatics 1977;18:2124.

35. Chae MS. Effects of personality preference, academic self-efficacy, and test anxiety on dentistry school students' academic achievement [master's thesis]. Gwangju: Graduate School of Chonnam National University; 2008.

36. Kim HS. The relationship among personality type, academic achievement and major satisfaction of junior college students. Keochang Jr Coll J 2001;4:141-155.

37. Huh J. An evaluation of senior high school administration in terms of Carl G. Jung's theory of personality type [master's thesis]. Seoul: Graduate School of Kyunghee University; 1991.

38. Kim S, Kim JH, Hur YR. A proposal on educational method of studying by comparing medical students' personality types and class achievement. Korean J Med Education 2005;17:107-119. 